Editorial

\title{
Inaugural Editorial of Urban Planning
}

\author{
Luca D'Acci $^{1}$, Tigran Haas ${ }^{2}$ and Ronita Bardhan ${ }^{3}$ \\ ${ }^{1}$ Institute for Housing and Urban Development Studies, Erasmus University Rotterdam, 3062 PA Rotterdam, \\ The Netherlands; E-Mail: dacci@ihs.nl \\ ${ }^{2}$ School of Architecture and Built Environment, KTH Royal Institute of Technology, 10044 Stockholm, Sweden; \\ E-Mail: tigran.haas@abe.kth.se \\ ${ }^{3}$ Centre for Urban Science and Engineering, Indian Institute of Technology Bombay, Powai, 400076 Mumbai, India; \\ E-Mail: ronita.bardhan@iitb.ac.in
}

Submitted: 15 December 2015 | Published: 8 February 2016

\begin{abstract}
This editorial is the introductory piece of Urban Planning, a new international peer-reviewed open access journal of urban studies aimed at advancing understanding of and ideas about humankind's habitats in order to promote progress and quality of life.
\end{abstract}

\section{Keywords}

future cities; progress; urban forms; urban planning

\section{Issue}

This editorial is part of the issue "Urban Forms and Future Cities", edited by Luca D'Acci (Erasmus University Rotterdam, The Netherlands), Tigran Haas (KTH Royal Institute of Technology, Sweden) and Ronita Bardhan (Indian Institute of Technology Bombay, India).

(C) 2016 by the authors; licensee Cogitatio (Lisbon, Portugal). This article is licensed under a Creative Commons Attribution 4.0 International License (CC BY).

\section{Humanistic and Scientific Approaches to Understanding Cities}

Understanding cities by the knowledge of their complex emergence from bottom up evolutions is essential to designing plans. The latter should be aimed at advancing humankind's habitats and identifying patterns toward progress and quality of life at different scales and angles. This understanding and planning process is based on the premise that qualitative linked to quantitative approaches provide mutually sympathetic outcomes for adding knowledge to the complex and polyhedral system par antonomasia as the city is.

The quantitative-scientific approach finds universal rules, viewing cities as part of the natural domain to be studied by scientific method. The humanistic approach claims a difference between the human and the natural domains, so studying cities and their phenomena quantitatively may lead to reductionism. Accordingly, this approach finds soft hermeneutic methods more suitable.

This opposition is only a surface-deep as it is often transformed into a profitable complementarity; that is using scientific methods when dealing with urban phenomena that are objective and universal, and the humanistic approach for phenomena that are not. We can also, when possible, quantify qualitative phenomena and qualitatively interpret quantified data. Sometimes quantifications without qualitative guides may be blind as well as the vice versa narrow.

The view of the world has repeatedly shifted between these two pendulums: scientific and humanistic. During the first half of the 20th century, both sides were present; the system theory approach was preeminent and, during the 50's, this induced researchers to see systems as centrally ordered, and as a hierarchical sum of subsystems dominated by negative feedback. Until the middle of the 20th century, a standard theory of cities as an economic and transportation model prevailed, based predominantly on the monocentric city. Ideas and models were built on statistical aggregations of units.

In the 1950's the quantitative revolution criticized 
the scientific validity of the humanistic trend, which defined descriptive approaches. In turn, in the early 1970's, scholars adopting urban social theories in the qualitative revolution criticized the positivist-quantitative approach.

The relatively recent science of urban complexity can be seen as a second scientific culture of cities, or, as I like, a junction between the scientific and humanistic cultures. Similarly, we often read the art of making cities versus the science of making cities, where art is viewed as the opposing counterpart to science. If for art we do not intend "beauty" - which is a fluctuating and baffling phenomenon-but intuition, then what we expect for a city to be a work of art is a personal element. Each city reveals unique features; each city is special, and in a different way for each of us.

The contemporary new science of cities, based on the complexity paradigm, is a science that induces art: each city emerges from unique contexts, from which the randomness of micro-fluctuations, the unpredictability of positive feedback on the agent's behaviour, and contextual historic successions, generate unique scenarios, each of them personally read. At the same time scientists clearly show a universality in several urban phenomena, independently from where they are situated. Science sees the many in the one, art the one in the many, and this happens without the classical contradictions of art versus science, and of qualitative versus quantitative.

It is my wish that this opening should encourage a vibrant mixed-method community to strive towards a gainful use of the great promise offered by a multidisciplinary connection and the synergy of qualitative and quantitative sciences to understand and design our habitats.

Luca D’Acci

\section{A Major Shift in Envisioning the Cities of the Future}

The complexities of contemporary global urban, political, economic, and environmental issues are evident. It is not hyperbole to say that human beings are now confronted with the greatest challenge that we have ever faced; in fact, it is a matter of life and death. The planet has recently been experiencing a convergence of natural and human-made crises that are unprecedented in our lifetime.

As we move toward 2050 we are facing the consequences of accelerating-rapid urbanization and population growth, the rise of mega-cities and mega-regions, the scarcity of natural resources and their mismanagement, the impact of major errors in our responses to disasters, and the increasing demand for and complexity of greatly expanding transportation flows. Our societies have also undergone rapid and radical shifts in terms of age and class, increasing inequities between the rich and poor and intense demands for de- mocracy in the public realm.

With the lack of a dominating paradigm in urban design and planning, we need to take a more thorough inquiry into the postmodern condition of cities. Various paradigms point to different forms of and approaches to design intervention in the public realm-each with conscious expectations, results, and consequences for the end users. Forces of structural and emergent change contribute to shaping the urban landscape and living infrastructures, presenting constant challenges for different measures for the reinvention of cities to be put in place. The importance of the digital and social media and network society in general, with its specific transformation and creation of new spaces and places is yet to be adequately explored.

The quality and the livability of the urban environment in our cities, towns, districts and neighborhoods are the deciding factors in the social, cultural, economic and environmental performance of societies and the quality of life of all their citizens. Our current studies need to encompass the history, culture and heritage management of cities. Previous studies in different fields, such as sociology, geography, architecture, environmental psychology, economics, etc. have explored people's social behaviour and relationships with urban space. Unfortunately the findings of each of these fields remained just that-findings of different fields. There was no real attempt made to unify the rich data generated within each discipline in order to shed more light on which and what kinds of urban environments were more conducive to human life in cities.

There is obviously a paradigm shift on the horizon in urban planning and urban design, emphasizing its benefits for sustainable urban development through a people-centered approach. Traditionally, the focus of urban development has been on the hardware of cities (buildings and infrastructure), instead of the software (culture and place). There is a need to shift conventional urban thinking from objects to places.

The way forward is through sustainable (socialcultural-economic-ecological) and resilient cities: energy-efficient neighborhoods and districts and green urbanism, but also civic design that will help shape and organize the city on the basis of diversity, human scale and preservation. All of this requires immediate solutions but also a change in the worldviews of architects, urban planners, designers, landscape architects and urbanists. We need these professionals and experts to contribute their most imaginative, pragmatic, resilient, innovative and just solutions. New visions for neighborhood housing redevelopment should support a human, economic, social and cultural recovery and renewal. The systems and processes that we put in place to achieve these ends can be thought of as the "soft infrastructure" of the community. This includes formal societal services and institutions as well as the community's informal structure, a unique and context- 
specific web of voluntary organizations and social relationships. For any of this to happen, a major shift and change in habits, customs and adaptation to an uncertain future will be required from all citizens, and without a consensus of all, the vision of a sustainable and resilient urban world by 2050 will not be possible.

Tigran Haas

\section{Redefining City Planning Agendas under the Contextual Realm}

As we move towards an urbanized world, cities are becoming the inevitable space for human interaction. Until now, cities were treated as engines of economic growth and the major focus was on the infrastructure that drives the city. However, it is the intangible element of culture which is the soft function for enhancing cities' competitiveness. The socio-economic fabric of the city does not only depend on the social and economic structure of the city, but also on the physical configuration and the context of the space. Urban planning should recognize the synergy between culture, economy and spatial patterns, and this inter-dependency should be reflected in new city planning agendas. With globalization, we are designing economically competitive global cities to meet expectations, ignoring local natural inclinations. The global city needs connotation of the intrinsic cultural transfusion into the capitalist form.

When we design a new city, we generally have certain goals to meet. These goals are directed by the definition and description of the type of city we intend to develop, for example, a compact city, a smart city, an industrial city, etc. The definition generally contains goals regarding the hardware, i.e. housing and infrastructure needs, density targets and economic motivations. But what are generally compromised are the context development objectives. This results in similar looking cities with rows of concrete structures packed within the space as per requirements. The inherent contextual and cultural setting which identifies and gives an 'image to the city becomes secondary. According to Sen (2004) "cultural matters are integral parts of the lives we lead. If development can be seen as enhancement of our living standards, then efforts geared to development can hardly ignore the world of culture". In the absence of it, the people residing there do not identify with the city and thus the 'sense of belonging' slowly dissipates (the community becomes egocentric) and thus the inhabitants do not 'give back' to the city.

It is often argued that it is the people and the kind of activity happening there that gives the city its identi- ty and culture. Thus, its image should develop organically with passage of time as it has happened with old cities. But the major difference between the evolution of old cities and new cities is that even the physical form of the city was previously developed organically, and this does not happen in new cities. Any type of activity or human interaction needs a particular type of physical space, and when this physical space itself cannot develop organically, the development of the culture or the image of the city becomes less flexible. For example, to sustain a vibrant street culture, the city needs to make provision for the volumetric cultural space (physical space, for example wide footpaths for vendors, shops and sitting areas, and competitive economic space) along the roads. Without such provisions, development of the vibrant street culture is likely not possible and in turn inherently impedes walkability.

Future cities would need a quintessential shift in thinking to provide contextual culture solutions to the neo-urban challenges. And now is probably the most suitable time to initiate this change. With the advent of Big Data and its integration with geo-spatial technologies, an enthusiasm for better understanding and managing cities with new and more extensive sources of data has emerged. Both urbanization and big data are unprecedented in their scope and can change irreversibly how cities will be run. This is currently generating a space for quantifying the culture and context of place. The prospect of using big data in urban planning is an "obvious opportunity to understand urbanism as a way of life". Despite this scope, the relationship between big data and urbanism is yet to be formalized. Since urban planning is more about unearthing how citizens behave in the physical environment, hence it is necessary to forecast these human behaviour chains, which is the fundamental capacity of big data analysis. However, many other computational issues associated with such large data sets need to be addressed. There is a need for conceptual frameworks that can resolve these existing dilemmas.

Ronita Bardhan

\section{Conflict of Interests}

The authors declare no conflict of interests.

\section{Reference}

Sen, A. (2004). Elements of a theory of human rights. Philosophy and Public Affairs, 32(4), 315-356. 


\section{About the Authors}

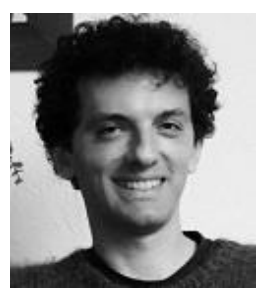

\section{Dr. Luca D'Acci}

Luca D'Acci is the Head of Urban Management and Climate Change of the Institute for Housing and Urban Development Studies at Erasmus University Rotterdam, and an Honorary Research Fellow at the University of Birmingham.

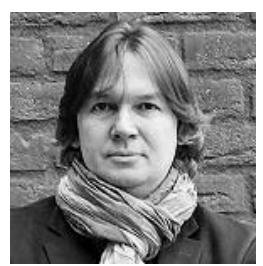

\section{Dr. Tigran Haas}

Tigran Haas is an Associate Professor and Reader of Urban Planning \& Urban Design at the School of Architecture and the Built Environment at KTH Royal Institute of Technology. He is the Founder and Director of the Civitas Athenaeum Laboratory (CAL), Applied Social Science Research Platform at KTH and the Director of Graduate Studies in Urbanism.

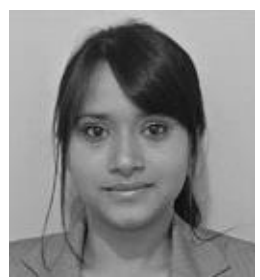

\section{Dr. Ronita Bardhan}

Ronita Bardhan is an Assistant Professor at the Centre for Urban Science and Engineering at The Indian Institute of Technology Bombay. She holds a PhD in Urban Engineering and is also a member of the Council of Architecture in India and IEEE-GRSS. 